\title{
Mortality in out-of-hours emergency medical admissions - more than just a weekend effect
}

\author{
${ }^{1} \mathrm{~F}$ Maggs, ${ }^{2} \mathrm{M}$ Mallet \\ ${ }^{1}$ Specialty Registrar in Acute Medicine; ${ }^{2}$ Consultant Physician in Acute Medicine, Royal United Hospital, Bath, UK
}

\begin{abstract}
Mortality among emergency medical admissions to hospital is higher for admissions at the weekend than on weekdays; this also holds true for certain specific conditions. However, it is unknown whether that effect is limited to weekends. This study calculated mortality in emergency medical admissions for each day of the week, and compared mortality at weekends with weekdays, at nights with days, and in all out-of-hours periods with in-hours in a UK district general hospital. Total mortality was increased for admissions on Mondays, at night, and in all out-of-hours periods; late in-hospital mortality (after seven days) remained increased when the initial admission occurred on Mondays, at night or out of hours. It is likely that illness severity as well as resource and organisational factors are involved.
\end{abstract}

KEYWORDS Emergencies, mortality, out of hours, weekends

DECLARATION OF INTERESTS No conflict of interests declared.

\section{INTRODUCTION}

Increasing evidence has accumulated over the past few years demonstrating a difference in mortality among emergency admissions to hospital at the weekend compared with weekdays. This effect is also true when considering only deaths within the first two days of admission. ${ }^{1-3}$ In large studies, mortality has also been reported to be increased for weekend admissions with specific medical conditions such as myocardial infarction, ${ }^{4}$ heart failure, ${ }^{5}$ upper gastrointestinal bleeding, ${ }^{6,7}$ pulmonary embolism, ${ }^{8}$ stroke ${ }^{9}$ and intracerebral haemorrhage, ${ }^{10}$ although a single-centre UK study of six specific medical conditions failed to demonstrate this effect." Worse outcomes have been reported for patients admitted outside normal working hours with myocardial infarction ${ }^{12}$ and in 'night-time' $(6 \mathrm{pm}-8 \mathrm{am})$ admissions to some intensive care units. ${ }^{13}$ Unexpected deaths were found to be more common among night-time emergency medical admissions in a UK pilot study of quality of care issues. ${ }^{14}$

We explored this variation in mortality for emergency medical admissions further, by investigating whether individual day of the week of admission was related to outcome, and whether admission at night or during any out-of-hours period, as well as at the weekend, was associated with an increased mortality.

\section{METHODS}

Anonymised hospital activity data were examined retrospectively for all non-elective admissions to a medium-sized UK district general hospital in the year April 2007 to March 2008. Over this time period, I 5,594 adults were admitted under the care of a physician. A further I,91। 'medical' patients, including I,014 with
Correspondence to $\operatorname{Dr} M$ Mallet Medical Assessment Unit, Royal United Hospital, Combe Park, Bath BAI 3NG, UK

tel. $+44(0) 1225821279$

e-mail mark.mallet@ruh.nhs.uk deliberate self-harm, were managed within the emergency department observation unit, and these are not included in our data analysis.

In-hospital mortality was determined according to the day of the week and the time of day of admission. In order to avoid a potential 'Monday' effect related to the end of the weekend period, we calculated mortality for each day of the week as 24 hours from 0800 , such that Monday 'take day' admissions are those admitted from Monday 8 am to Tuesday $8 \mathrm{am}$.

We then compared mortality for admissions at weekends (midnight Friday to midnight Sunday) versus weekdays, nights ( $9 \mathrm{pm}-8 \mathrm{am})$ versus days, and all out-of-hours periods versus in hours ( $8 \mathrm{am}-5 \mathrm{pm}$, Monday to Friday). We carried out these analyses for overall mortality and 'late' mortality defined as in-hospital deaths beyond the first seven days.

In the definition of out of hours versus in hours, public holidays were counted as normal days.

\section{Statistical analysis}

Chi-squared tests were carried out to examine the relationship between the day of week of admission and mortality rates. Comparison of mortality rates among patients admitted at the weekends with those admitted during the week, at night rather than during the day, and out of hours with in hours, were analysed using a logistic regression model adjusted for age and sex. Age was categorised as 0-19 years, 20-39 years, 40-59 years, $60-79$ years and $\geq 80$ years.

Unadjusted and adjusted odds ratios (OR) were calculated, with the corresponding $95 \%$ confidence 


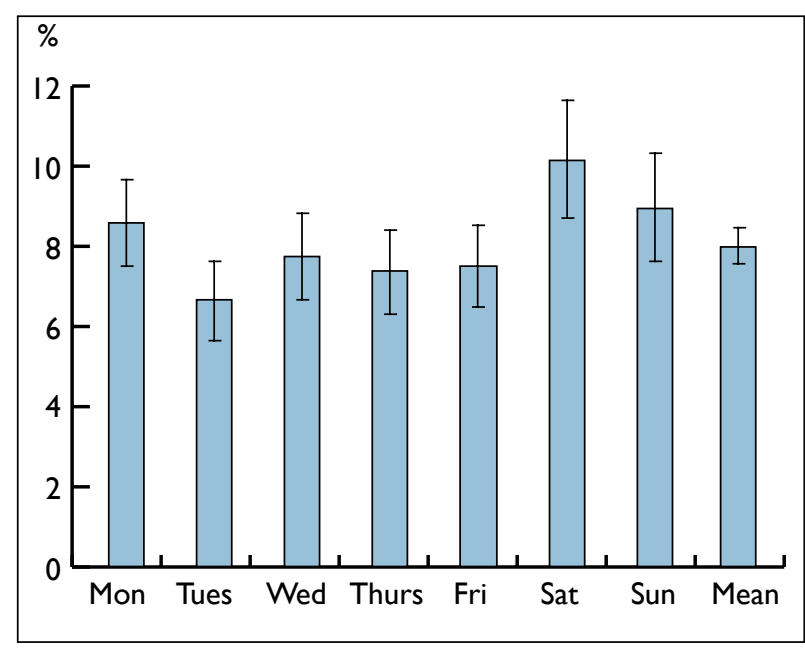

FIGURE I Mortality rate (mean and $95 \%$ confidence intervals) by take day of admission: all deaths.

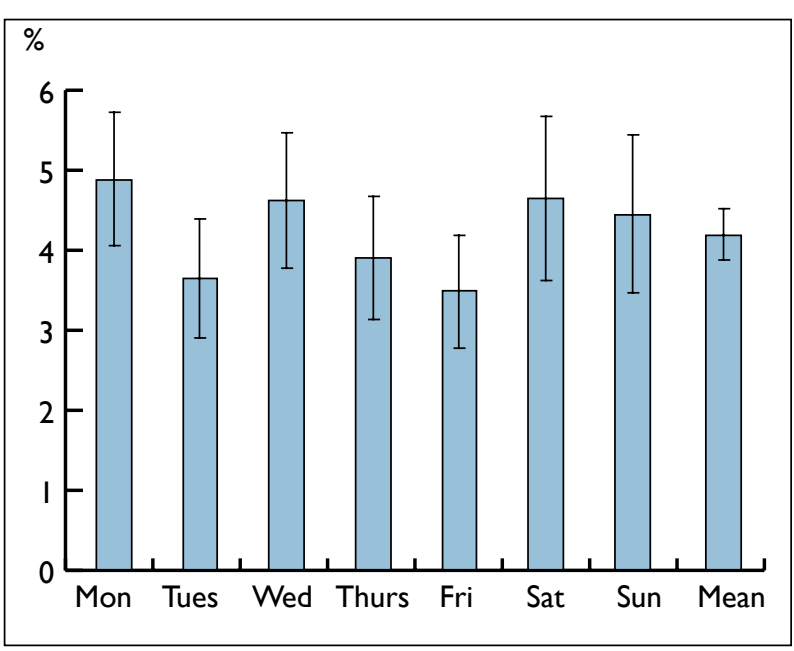

FIGURE 2 Mortality rate (mean and $95 \%$ confidence intervals) by take day of admission: late deaths ( $>7$ days).

interval $(\mathrm{Cl})$ for the adjusted OR. Significance levels for $\mathrm{p}$-values are at the two-sided $5 \%$ level.

\section{RESULTS}

Of the 15,594 admissions under medical consultants, 7,598 (48.7\%) were men. Median age was 72 years and mean 67.4 years (range 16-106); 32\% of patients were aged 80 years or more. The most common diagnostic group was non-cardiac chest pain (1,392 admissions), accounting for $8.9 \%$ of all non-elective activity. Overall, hospital mortality for emergency medical admissions was $7.96 \%$.

\section{Mortality by day of week of admission}

Mortality varied by day of week of admission. Unadjusted analyses of mortality on each day of the week demonstrate significant relationships between take day and death rates for overall mortality $(p=0.007)$. Admissions on Mondays have a higher overall death rate than admissions on other weekdays (Figure I).
TABLE I Mortality by day and time of admission: all deaths

\begin{tabular}{|c|c|c|c|c|c|c|c|}
\hline 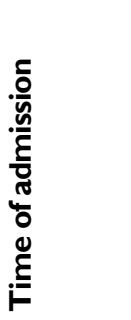 & 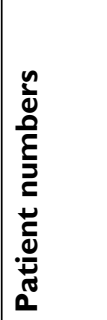 & 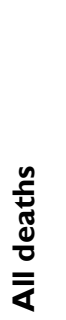 & 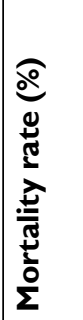 & 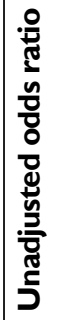 & 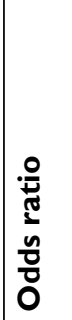 & 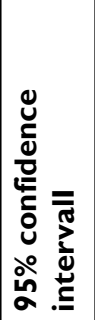 & $\begin{array}{l}\frac{0}{2} \\
\frac{2}{2} \\
\text { d. }\end{array}$ \\
\hline Weekend & 3,219 & 290 & 9.01 & \multirow[t]{2}{*}{1.19} & \multirow[t]{2}{*}{1.11} & \multirow{2}{*}{$\begin{array}{l}0.97- \\
1.25\end{array}$} & \multirow[t]{2}{*}{0.13} \\
\hline Weekday & 12,375 & 951 & 7.68 & & & & \\
\hline Nights & 4,847 & 459 & 9.47 & \multirow[t]{2}{*}{1.33} & \multirow[t]{2}{*}{1.32} & \multirow{2}{*}{$\begin{array}{l}1.20- \\
1.45\end{array}$} & \multirow[t]{2}{*}{$<0.001$} \\
\hline Days & 10,747 & 782 & 7.28 & & & & \\
\hline $\begin{array}{l}\text { Out of } \\
\text { hours }\end{array}$ & 9,910 & 890 & 8.98 & \multirow[t]{2}{*}{1.50} & \multirow[t]{2}{*}{1.37} & \multirow[t]{2}{*}{$\begin{array}{l}1.24 \\
1.50\end{array}$} & \multirow[t]{2}{*}{$<0.001$} \\
\hline In hours & 5,684 & 351 & 6.18 & & & & \\
\hline
\end{tabular}

TABLE 2 Mortality by day and time of admission: late deaths

\begin{tabular}{|c|c|c|c|c|c|c|c|}
\hline 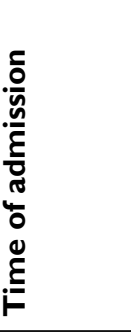 & 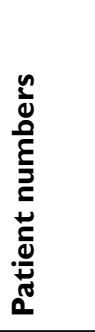 & 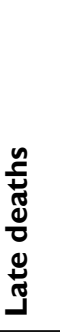 & 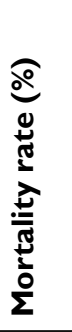 & 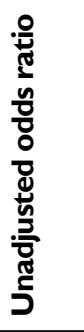 & 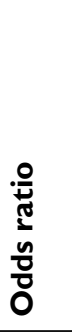 & 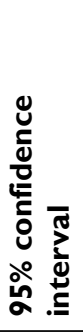 & $\begin{array}{l}\frac{0}{2} \\
\frac{\pi}{n} \\
\frac{1}{2}\end{array}$ \\
\hline Weekend & 3,219 & 132 & 4.10 & \multirow[t]{2}{*}{0.965} & \multirow[t]{2}{*}{0.89} & \multirow{2}{*}{$\begin{array}{l}0.70- \\
1.09\end{array}$} & \multirow[t]{2}{*}{0.27} \\
\hline Weekday & 12,375 & 525 & 4.24 & & & & \\
\hline Nights & 4,847 & 246 & 5.08 & \multirow[t]{2}{*}{1.34} & \multirow[t]{2}{*}{1.33} & \multirow{2}{*}{$\begin{array}{l}1.16- \\
1.49\end{array}$} & \multirow[t]{2}{*}{$<0.001$} \\
\hline Days & 10,747 & 411 & 3.82 & & & & \\
\hline $\begin{array}{l}\text { Out of } \\
\text { hours }\end{array}$ & 9,910 & 477 & 4.81 & \multirow[t]{2}{*}{1.55} & \multirow[t]{2}{*}{1.40} & \multirow[t]{2}{*}{$\begin{array}{l}1.22- \\
1.58\end{array}$} & \multirow[t]{2}{*}{$<0.001$} \\
\hline In hours & 5,684 & 180 & 3.17 & & & & \\
\hline
\end{tabular}

Across the whole week, there also appears to be a significant correlation between the take day of admission and late mortality $(p=0.00 \mathrm{I})$, with the highest death rate being on Mondays (Figure 2).

\section{Mortality by day and time of admission}

After adjusting for age and sex, we did not detect a significantly increased overall mortality in patients admitted at the weekend compared with those admitted on weekdays. However, total mortality was increased in patients admitted at night compared with those admitted in the daytime, and in all out-of-hours periods taken together compared with normal working hours (Table I).

For patients dying after a length of stay greater than seven days, there was no significant difference in the mortality rate for weekend admissions, after adjusting for age and sex. However, late mortality was increased for those originally admitted at night or in all out-ofhours periods considered together (Table 2). 


\section{DISCUSSION}

Hospital standardised mortality ratios (HSMRs) calculated by Dr Foster Intelligence are widely used to compare outcomes between different hospitals or identify trends over time within the National Health Service (NHS), although the validity of these comparisons has recently been questioned. ${ }^{15}$ An analysis of activity data for the whole NHS showed that HSMRs for emergency medical patients in 2007-08 were significantly higher for admissions at the weekend, compared with weekdays, ${ }^{16}$ and mortality for emergency weekend admissions across England in 2005-06 was 10\% higher than for weekday admissions. ${ }^{3}$ Our present single-centre analysis of non-standardised mortality for emergency medical admissions has not demonstrated such a difference at the weekends, but our data do suggest an excess mortality for admissions on Mondays compared with the rest of the week, for patients admitted at night compared with during the daytime, and for all out-ofhours admissions compared with in-hours. Although these findings need to be confirmed in larger studies, this appears not to be just a weekend effect.

Emergency medical admissions in the UK have increased substantially over the past ten years. Attempts to establish an appropriate 24/7 inpatient service for these patients have been hampered by limitations in resources, targets for elective work and restrictions on working hours for doctors in training. Outside the hospital, the delivery of acute care within local health communities throughout the whole 24/7 period has also developed over the past few years, with a change in out-of-hours provision of general practice along with an expansion in the variety of available options for patients.

\section{Patient and pre-hospital factors}

Are patients who present to hospital out of hours more unwell than those admitted during the normal working day? This is difficult to clarify, as current scores of illness severity do not have particularly good discrimination. However, in one recent study, out-of-hours admissions to three intensive care units were found to have higher illness severity, as measured by APACHE II and SAPS II scores, and this was associated with increased mortality. ${ }^{17}$ In our cohort, patients admitted at the weekend who survived the first seven days do not have a higher subsequent mortality rate, but those admitted on Monday take days, at night or out of hours do appear to have a worse outcome even if they survive the first seven days. We postulate that these differences in late mortality are more likely to be explained by variation in initial illness severity, since any in-hospital factors around the time of admission would be expected to have less impact after seven days. It is suggested that patients who initially present to hospital at these times may on average be more severely ill, compared with those with lesser 'emergencies' who wait - or have been planned - for next-day normal daytime assessment.
A number of factors may be involved: for example, availability of transport either during normal working hours or out of hours may affect day and time of arrival in hospital; patients may have perceived or real difficulties in accessing primary care services at night or over the weekend, perhaps presenting to hospital on Mondays with more developed illness than on other days; out-ofhours primary care co-operatives may provide care differently to patients' own general practitioners during normal working hours; and end-of-life support and decision-making may be different at different times of the day or week, with the result that dying patients are more likely to be admitted to hospital in out-of-hours periods. It is also our practice to defer the assessment to the next day of some less unwell patients referred out of hours.

Several studies have shown that hospital mortality can be predicted on the basis of illness severity scores calculated at the time of admission, either in the emergency department, ${ }^{18,19}$ an assessment unit ${ }^{20,21}$ or a medical ward. ${ }^{22}$ None of these studies looked at whether the average early warning scores varied according to time or day of admission; although such scores are somewhat blunt tools, this analysis may be a useful next step to help our understanding of the variation in mortality we have observed.

\section{Delivery of inpatient care}

How much of the variation in mortality can be explained by differences in the delivery of care in hospital during out-of-hours periods? Reduced overall staffing levels, less senior and less experienced staff, cross cover for other clinicians' patients, and less supervision have all been quoted as possible explanations for the 'weekend effect'.' All of these factors also apply at night, as well as a possible average increase in the time to first consultant review. Similar issues are cited as possible contributory factors to a reduced survival from in-hospital cardiac arrest at nights and at weekends. ${ }^{23}$ Many or all of these issues may be relevant here.

Differences in outcome depending on time and day of admission may therefore reflect both patient and prehospital factors (how sick they are by the time they arrive in hospital) and hospital factors (resource and organisational issues). The relative contribution of these is unknown, and further work needs to be done to distinguish illness severity elements from those relating to the delivery of care in hospital. While continued efforts need to be made to address any possible responsible in-hospital factors, the whole local health community needs to address why unwell patients seem to have a worse outcome after being admitted to hospital out of hours: in some way their needs are apparently not being addressed adequately through the complex systems and interfaces of primary and secondary care that are currently in place. 


\section{Limitations}

Our study has a number of limitations. Because of the multiple statistical analyses carried out, a degree of caution needs to be applied with regard to the interpretation of our findings. We did not correct for any underlying illnesses or comorbidities. Small numbers may have contributed to the lack of statistical significance. There may be some lead-time bias, since the time of admission as recorded in the hospital episode statistics is not necessarily the same as the time of arrival in hospital, if patients have been assessed in the emergency department before being 'admitted' to the acute medical unit. This is a single-centre study, and the particular way in which primary care services are delivered and interface with secondary care may be quite different to other locations. In addition, national holidays (including five Mondays) have not been included in the out-of-hours or weekend data but were treated as normal working days.

\section{CONCLUSION}

Overall mortality for emergency medical admissions in this UK district general hospital is not significantly increased at weekends, but appears to be greater on

\section{REFERENCES}

I Bell CM, Redelmeier DA. Mortality among patients admitted to hospitals on weekends as compared with weekdays. N Engl J Med 200I; 345:663-68. doi:I0.1056/NEJMsa003376

2 Barba R, Losa JE, Velasco M et al. Mortality among adult patients admitted to the hospital on weekends. Eur J Intern Med 2006; 17:322-4. doi:10.10I6/j.ejim.2006.01.003

3 Aylin P,Yunus A, Bottle A et al. Weekend mortality for emergency admissions. A large multicentre study. Qual Saf Health Care 2010; epub ahead of print 28 Jan. doi: I0.I I36/qshc.2008.028639

4 Kostis WJ, Demissie K, Marcella SW et al. Weekend versus weekday admission and mortality from myocardial infarction. $N$ Engl J Med 2007; 356:1099-109. doi:10.1056/NEJMoa063355

5 Horwich TB, Hernandez AF, Liang $L$ et al. Weekend hospital admission and discharge for heart failure: association with quality of care and clinical outcomes. Am Heart J 2009; 158:45I-8. doi:I0.1016/j.ahj.2009.06.025

6 Ananthakrishnan AN, McGinley EL, Saeian K. Outcomes of weekend admissions for upper gastrointestinal hemorrhage: a nationwide analysis. Clin Gastroenterol Hepatol 2009; 7:296-302el.

7 Shaheen AA, Kaplan GG, Myers RP. Weekend versus weekday admission and mortality from gastrointestinal hemorrhage caused by peptic ulcer disease. Clin Gastroenterol Hepatol 2009; 7:303-I0. doi:10.1016/j.cgh.2008.08.033

8 Aujesky D, Jiménez D, Mor MK et al. Weekend versus weekday admission and mortality after acute pulmonary embolism. Circulation 2009; I 1 9:962-68. doi: I 0. I I 6 I/CIRCULATIONAHA. I08.824292

9 Saposnik G, Baibergenova A, Bayer $\mathrm{N}$ et al.Weekends: a dangerous time for having a stroke? Stroke 2007; 38: I2II-15. doi:I0.1 I6I/0I. STR.0000259622.786I6.ea

I0 Crowley RW, Yeoh HK, Stukenborg GJ et al. Influence of weekend hospital admission on short-term mortality after intracerebral hemorrhage. Stroke 2009; 40:2387-92. doi:10.1I6I/ STROKEAHA. I08.546572

II Schmulewitz L, Proudfoot A, Bell D. The impact of weekends on outcome for emergency patients. Clin Med 2005; 5:62I-25.

12 Magid DJ,Wang Y, Herrin J et al. Relationship between time of day, day of week, timeliness of reperfusion, and in-hospital mortality
Mondays, at night and when all out-of-hours periods are taken together. Patients who are admitted on Monday take days, overnight or in any out-of-hours period remain more likely to die in hospital a week or more later; this may indicate a difference in their initial illness severity.

These tentative findings need confirming in a larger study. Further work is also needed to clarify the cause of these outcomes, and in particular to distinguish the patient and pre-hospital factors from the in-hospital factors. A prospective study of whether day and time of arrival in hospital affect average illness severity scores and therefore outcomes would go some way towards clarifying this issue, in order to determine how the whole health community can improve the care of these sickest patients.

Acknowledgment We are very grateful to Jane Temple (University of Bath) for help with statistics.

for patients with acute ST-segment elevation myocardial infarction. JAMA 2005; 294:803-12. doi: 10.100I/jama.294.7.803

I3 Laupland KB, Shahpori R, Kirkpatrick AW et al. Hospital mortality among adults admitted to and discharged from intensive care on weekends and evenings. J Crit Care 2008; 23:317-24. doi:10.1016/j. jcrc.2007.09.00I

14 Seward E, Greig E, Preston S et al. A confidential study of deaths after emergency medical admission: issues relating to quality of care. Clin Med 2003; 3:425-34.

15 Black N. Assessing the quality of hospitals. BMJ 2010; 340:c2066. doi:10.II36/bmj.c2066

16 Jones S, Barnett N. Data briefing. Why admission day affects outcomes. Health Serv J 2008 Oct 30:17.

17 Meynaar IA, van der Spoel JI, Rommes JH et al. Off hour admission to an intensivist-led ICU is not associated with increased mortality. Crit Care 2009; I3:R84. doi: I0.I I86/cc7904

18 Burch VC, Tarr G, Morroni C. Modified early warning score predicts the need for hospital admission and inhospital mortality. Emerg Med J 2008; 25:674-8. doi:I0.I I36/emj.2007.05766I

19 Goodacre S, Turner J, Nicholl J. Prediction of mortality among emergency medical admissions. Emerg Med J 2006; 23:372-5. doi:I0.II36/emj.2005.028522

20 Paterson R, MacLeod DC, Thetford D et al. Prediction of in-hospital mortality and length of stay using an early warning scoring system: clinical audit. Clin Med 2006; 6:28I-4.

2I Groarke JD, Gallagher J, Stack J et al. Use of an admission early warning score to predict patient morbidity and mortality and treatment success. Emerg Med J 2008; 25:803-6. doi:I0.1136/ emj.2007.05I425

22 Cei M, Bartolomei C, Mumoli N. In-hospital mortality and morbidity of elderly medical patients can be predicted at admission by the modified early warning score: a prospective study. Int J Clin Pract 2009; 63:59I-5. doi:10.IIII/j.I742-124I.2008.01986.x

23 Peberdy MA, Ornato JP, Larkin GL et al. Survival from in-hospital cardiac arrest during nights and weekends. JAMA 2008; 299:78592. doi:I0.100I/jama.299.7.785 